\section{Celebrating 50 years of heart trans- plant surgery: A missed opportunity to honouir Hamilton Naki}

To the Editor: 2017 marked the 50th anniversary of the first human heart transplant in South Africa. To commemorate this, Brink et al. ${ }^{[1]}$ published a guest editorial in the December 2017 issue of the SAMJ. The authors from the Christiaan Barnard Division of Cardiothoracic Surgery at Groote Schuur Hospital gave an overview of the evolution of transplant surgery, from experimental work to clinical translation. This included a brief summary of the significant progress in immune-suppressive drug discovery that has led to the greater success of transplant medicine. A reprint of the teams involved was also published, and as expected reflects the racial environment during that time. It saddened us, however, that in a modern account of this innovative leap in medicine there is still a failure to acknowledge the roles of black members, such as Hamilton Naki, in the laboratory research process towards human surgical transplantation. There have indeed been some inaccurate accounts regarding Naki's involvement in the transplant team. ${ }^{[2]}$ Clarity about his evolving role as a laboratory technician and later a surgical assistant in the Marais animal laboratory was provided by then Emeritus Prof. John Terblanche ${ }^{[3]}$ in a 2005 letter in the SAMJ. Recognition of Mr Naki's achievement in the context of his educational background and racial disadvantage led to him being awarded the Order of Mapungubwe, a national honour by former President Thabo Mbeki, and an honorary Master of Medicine degree from the University of Cape Town. To honour such a person does not remove from the tremendous achievement of Prof. Barnard and his surgical team, whose first 2 patients survived longer than those of his US counterparts at the time. ${ }^{[4]}$ However, the failure to even mention Mr Naki seems an ongoing denial of the contributions of black South Africans to the advancement of science. This is a particularly inspiring story of what can be achieved even by the most disadvantaged when people work together regardless of racial background. Inspiration could be drawn from the story of Vivien Thomas. He was a black man, with a high-school diploma, who grew up in the 1900s in the south of the USA. He went on to become a laboratory assistant, contributing to pioneering work in the advancement of cardiovascular surgery. Although he was initially disregarded, he was later awarded an honorary doctorate and his portrait hangs alongside those of other medical pioneers at Johns Hopkins Medical School to inspire future scientists. ${ }^{[5]}$ In missing such an opportunity to inspire, we are left to wonder whether this was a wilful omission or innocent oversight by the authors.

\section{N Mankahla}

Division of Neurosurgery, Department of Surgery, Groote Schuur Hospital and Red Cross War Memorial Children's Hospital, Cape Town, South Africa ncedilemankahla@yahoo.com

\section{S Dlamini}

Division of Infectious Diseases, Department of Medicine,

Groote Schuur Hospital and University of Cape Town, South Africa

\section{C Taunyane}

Department of Cardiovascular Surgery, Heart Center, University of Freiburg, Germany

\section{S Maqungo}

Division of Orthopaedic Surgery, Department of Surgery,

Groote Schuur Hospital and University of Cape Town, South Africa

\section{Cairncross}

Department of Surgery, Groote Schuur Hospital and University of Cape Town, South Africa

\section{B Chiliza}

Department of Psychiatry, Nelson R Mandela School of Medicine, University of KwaZulu-Natal, Durban, South Africa

\footnotetext{
1. Brink J, Pennel T, Seele K, Zilla P. The world's first human-to-human heart transplant at Groote Schuu Hospital: 50 years later. S Afr Med J 2017;107(12):1035-1036. https://doi.org/10.7196/SAMJ.2017. v107i12

2. Kapp C. Hamilton Naki. Lancet 2005;366(2):22. https://doi.org/10.1016/S0140-6736(05)66811-0

3. Terblanche J. A standard of care? S Afr Med J 2005;95(8):539-540.

4. McKellar S. Clinical firsts - Christiaan Barnard's heart transplantations. N Engl J Med 2017;377(23):2211 2213. https://doi.org/10.1056/NEJMp1707919
}

5. Kennedy DM. In search of Vivien Thomas. Tex Heart Inst J 2005;32(4):477-478.

S Afr Med J 2018;108(3):151. DOI:10.7196/SAMJ.2018.v108i3.13114 